\title{
WHY DO POLYGYNOUS UNGULATES SEGREGATE IN SPACE? TESTING THE ACTIVITY-BUDGET HYPOTHESIS IN SOAY SHEEP
}

\author{
F. J. Pérez-Barbería,${ }^{1,4}$ E. Robertson,,${ }^{1}$ R. Soriguer,${ }^{2}$ A. Aldezabal,${ }^{3}$ M. Mendizabal, ${ }^{3}$ and E. Pérez-Fernández ${ }^{1}$ \\ ${ }^{1}$ The Macaulay Institute, Craigiebuckler, Aberdeen, Scotland AB158QH UK \\ ${ }^{2}$ Estación Biológica de Doñana, C.S.I.C. Apartado 1056, Sevilla 41013 Spain \\ ${ }^{3}$ Landare Biologia eta Ekologia Saila, Zientzia eta Teknologia Fakultatea, Euskal Herriko Unibertsitatea (UPV-EHU), 644 p.k., \\ 48080 Bilbo (Bizkaia), Euskal Herria, Spain
}

\begin{abstract}
Sexual segregation is the behavior in which animals of different sex in a species live in separate groups outside the mating season. Recently a new concept, namely, the "activity-budget hypothesis," has claimed to be the ultimate explanation of this behavior. The new hypothesis explains not only sexual segregation, but also segregation between animals of different size within sex (i.e., social segregation). The hypothesis states that the activity patterns of animals will differ when big differences in body mass exist between them, because of the associated difficulties of the synchronization in behavior making it costly to form groups, leading to segregation by size. Here we tested the assumptions and predictions of the activity-budget hypothesis using 40 Soay sheep (Ovis aries) as the model species in a 2.3-ha experimental arena. Sheep were divided into treatment groups to test the effect of sex, body mass, and food supplementation in their activity budgets, behavioral synchronization, diet composition, intake, food digestibility, and spatial segregation. Our animals segregated by sex but not by size, and food supplementation did not affect the spatial distribution of any sex, which is all against the predictions of the hypothesis. We also found sexual differences in drymatter digestibility independent of body mass, which questions the Jarman-Bell principle at the intra-specific level, which is the foundation for some other hypotheses of sexual segregation. Increasing behavioral synchronization led to segregation, but at the same time forming groups facilitates synchronization, so it is unclear which (i.e., synchronization or segregation) is the cause and which the consequence. Our results do not support the activitybudget hypothesis and clearly indicate that there is no strong association between behavioral synchronization and segregation.
\end{abstract}

Key words: activity-budget hypothesis; behavior; sexual segregation; Soay sheep; spatial distribution; synchronization.

\section{INTRODUCTION}

Sexual segregation is the behavior in which animals of different sex live in separate groups outside the mating season (Ruckstuhl and Neuhaus 2005a). This behavior is widespread across most of ungulate species that show significant sexual dimorphism in body mass (Ruckstuhl and Neuhaus 2002), but it has also been recorded in a variety of other vertebrate taxa such as fish (Croft et al. 2005), reptiles (Shine and Wall 2005), birds (GonzalezSolis and Croxall 2005), bats (Altringham and Senior 2005), marsupials (MacFarlane and Coulson 2005), seals (Staniland 2005), odontocetes (Michaud 2005), and primates including humans (Pellegrini et al. 2005, Watts 2005). Darwin (1859) articulated the basis of sexual segregation when he stated the importance of sex differences in habitat use in relation to sexual selection. Since this behavior has implications in the biology, ecology, evolution and management of many species, understanding the driving mechanisms has received a

Manuscript received 18 December 2006; revised 28 February 2007; accepted 7 March 2007. Corresponding Editor: B. P. Kotler.

${ }^{4}$ E-mail: j.perez-barberia@macaulay.ac.uk great deal of attention from the scientific community in recent years (Ruckstuhl and Neuhaus 2005a).

A milestone in the understanding of sexual segregation in ungulates was set up by Main et al. (1996), who classified a plethora of existing hypotheses into three categories:

(1) The predation-risk or reproductive-strategy hypothesis states that males and females differ in habitat use because of the different roles that both sexes have in reproduction. Male reproductive strategy is based on maximizing body size to gain competitive supremacy and access to mates (Clutton-Brock et al. 1982, Prins 1989), whereas females with offspring will choose predator-safe habitats even if this is at the expense of food intake (Main and Coblentz 1996, Corti and Shackleton 2002).

(2) The forage-selection or sexual-dimorphism-bodysize hypothesis claims that allometric differences in body size (i.e., energy requirements scaling at 0.75 body mass, while gut volume scales to a factor of 1.0 body mass; Demment 1982, Pérez-Barbería et al. 2001) result in larger individuals having less energy requirements per unit of body mass. In addition, this enables large 
animals to increase the time that food is retained in their digestive tract and consequently increases their efficiency in digesting fiber (Robbins 1993). Therefore, it has been hypothesized that males of polygynous species, in which males are larger than females, can use habitats in which food is less digestible but more abundant than the food available in the habitats used by females (Demment 1982, Clutton-Brock and Harvey 1983, Demment and Longhurst 1987, Illius and Gordon 1987, Barboza and Bowyer 2000).

(3) The social-factors hypothesis states that males and females differ in their ontogenetic behavior, because different levels of activity and patterns of interaction (males forming associations to develop fighting skills) are of paramount importance for males to have access to mates during the rut, promoting social auto-segregation by sex and age classes (Bon and Campan 1996, Bon et al. 2005, Pérez-Barbería et al. 2005).

A recent concept known as the activity-budget hypothesis has received special attention in the sexualsegregation literature (Conradt 1998, Ruckstuhl 1998, 1999, Ruckstuhl and Neuhaus 2000, 2001, 2002, 2005a, Neuhaus and Ruckstuhl 2002, Ruckstuhl and Kokko 2002, Mooring et al. 2003, Michelena et al. 2004, 2006) and has been the focus of passionate discussion (Mooring et al. 2003, Mooring and Rominger 2004, Neuhaus and Ruckstuhl 2004a,b). This hypothesis proposes that spatial segregation into sex groups or age classes arises when animals find it difficult to synchronize their behavioral activity due to differences in body mass (Ruckstuhl 1998). The hypothesis is based on two main assumptions (Ruckstuhl and Neuhaus 2002): (a) animals of small body size are less efficient at digesting fiber than larger ones, due to body-size digestive constraints (i.e., smaller stomach and faster passage rate of food through their digestive system; Demment 1982, Robbins 1993), and (b) big differences in activity budgets may make synchronization of behavior costly (Conradt 1998, Conradt and Roper 2003).

The predictions of the hypothesis are:

$\left(\mathrm{P}_{1}\right)$ Smaller animals will compensate for their lower digestive efficiency by more selective foraging (i.e., foraging longer), while larger animals will spend more time ruminating or lying to digest forage, because of their larger digestive tract.

$\left(\mathrm{P}_{2}\right)$ The probability of groups breaking up will be higher in those groups with animals of different size and consequently with different activity budgets in comparison with groups constituted of animals of similar size (Conradt 1998, Ruckstuhl and Neuhaus 2002).

The practicality of the activity-budget hypothesis is that it sets up a theoretical framework to explain not only sexual segregation in species dimorphic in body mass but also social segregation, that is, segregation between cohorts within sex, using a simple mechanistic concept based upon differences in body size.

It has been claimed that the activity budget is the underlying and proximate cause that leads to sexual segregation in sexually dimorphic ungulates (Ruckstuhl and Neuhaus 2002, Neuhaus and Ruckstuhl 2004a), although this has received serious criticisms (Mooring and Rominger 2004). Arguments to support the hypothesis are mainly based on observational field studies (Ruckstuhl and Neuhaus 2000, 2001, Neuhaus and Ruckstuhl 2002, Loe et al. 2006). However, in field studies it is difficult to evaluate the costs of synchronization in behavior. There have been some experimental (Mooring et al. 2003, Michelena et al. 2004, 2006) and modelling (Conradt and Roper 2000, Ruckstuhl and Kokko 2002, Yearsley and Pérez-Barbería 2005) attempts to test the hypothesis, but the findings were inconclusive. It is also questionable whether synchronization in behavior is the cause of segregation or a consequence (Barboza and Bowyer 2001, Bowyer 2004). However, supporters of the activity-budget hypothesis criticize the methods, assumptions and predictions used in some of these studies (Mooring and Rominger 2004, Neuhaus and Ruckstuhl 2004b) and they believe that these are the causes why the studies have failed to provide further evidence to support the hypothesis (Neuhaus and Ruckstuhl 2004a, b).

This study aims to test the assumptions and predictions of the activity-budget hypothesis using an experimental approach under controlled conditions with Soay sheep as the model species.

\section{Testing assumptions (Table 1)}

$\left(A_{1}\right)$ Females are less efficient at digesting forage than males. Here we generalize this assumption made in Ruckstuhl and Neuhaus (2002: Table 1) stating that small animals are less efficient at digesting forage than larger ones, regardless of their sex. This would help to explain social segregation.

$\left(\mathrm{A}_{2}\right)$ Differences in activity budgets make synchrony of behavior difficult and potentially costly. We measured and compared behavioral synchrony between groups that clearly differ in body mass. We also attempted to modify the amount of time of daily grazing of the animals by food supplementation to evaluate the power of this effect in modifying their patterns of behavioral synchronization.

\section{Testing predictions (Table 1)}

$\left(\mathrm{P}_{1}\right)$ From Ruckstuhl and Neuhaus (2002: Table 1) and Ruckstuhl and Neuhaus (2005b), females (or smaller animals) compensate for their lower efficiency at digesting fiber by foraging for longer than males (or larger animals), while males (or larger animals) spend more time than females (or smaller animals) ruminating or lying to digest forage.

$\left(\mathrm{P}_{2}\right)$ Animals with similar activity budgets form groups. We measured segregation and correlated it with behavioral synchronization in groups that differ in body mass and sex and also in groups in which sex and size are not confounded effects. 
TABLE 1. Design of group comparisons to test specific assumptions and predictions of the activity budget hypothesis and expected results in time spent foraging and spatial-distribution pattern (segregation or no segregation).

\begin{tabular}{|c|c|c|c|c|}
\hline \multirow[b]{2}{*}{ Group comparisons } & \multicolumn{2}{|c|}{ Testing } & \multicolumn{2}{|l|}{ Expected results } \\
\hline & Assumptions & Predictions & Time foraging & Segregation \\
\hline Male, small vs. large & $\mathrm{A}_{1}$ & $\mathrm{P}_{1}, \mathrm{P}_{2}$ & small $>$ large & yes \\
\hline Female, small vs. large & $A_{1}$ & $\mathrm{P}_{1}, \mathrm{P}_{2}$ & small $>$ large & yes \\
\hline Small male vs. large female $\dagger$ & $\mathrm{A}_{1}$ & $\mathrm{P}_{1}, \mathrm{P}_{2}$ & small male $=$ large female & no \\
\hline Male, supplemented vs. not supplemented & $\mathrm{A}_{2}$ & $\mathrm{P}_{1}, \mathrm{P}_{2}$ & supplemented $<$ not supplemented & yes \\
\hline Female, supplemented vs. not supplemented & $\mathrm{A}_{2}$ & $\mathrm{P}_{1}, \mathrm{P}_{2}$ & supplemented $<$ not supplemented & yes \\
\hline
\end{tabular}

Note: See Introduction: Testing assumptions and Testing predictions for further details.

$\uparrow$ No differences in body mass between small male and large female; this comparison is intended to test sexual differences free of body-size effect.

Finally, we attempted to unravel the cause and effect in the relationship between synchronization and segregation (Barboza and Bowyer 2001, Bowyer 2004).

\section{Methods}

\section{Study area and animals}

The experiment was carried out in accordance with the U.K. Home Office Animals (Scientific Procedures) Act 1986, at the Macaulay Institute's Glensaugh Research Station in the northeast of Scotland between 16 May and 10 June 2005. We used 40 mature Soay sheep, 20 males $(2-6$ years old, mean $=3.8 \mathrm{yr})$ and 20 dry females $(2-9$ years old, mean $=4.4 \mathrm{yr})$ forming three different groups within sex, namely, small, large, and supplemented, in relation to relative differences in body mass and treatment received. Sexual dimorphism in body mass between small and large groups was 26\% in males (small $=29.2 \pm 1.67 \mathrm{~kg}[$ mean $\pm \mathrm{SD}], n=5$ sheep; large $=39.4 \pm 1.85 \mathrm{~kg}, n=5$ sheep) and $32 \%$ in females $($ small $=21.4 \pm 0.90 \mathrm{~kg}, n=5$ sheep; large $=31.5 \pm 1.48$ $\mathrm{kg}, n=5$ sheep), well over the $20 \%$ threshold of sexual dimorphism that Ruckstuhl and Neuhaus (2002) claimed necessary to produce segregation in ungulate species. Consequently, under the activity-budget hypothesis it was expected that, within sex, small and large size groups segregate because of their differences in body mass. For comparisons between sexes free of the effect of body mass we compared small males against large females since between these two groups the sexual differences in body mass were negligible.

All animals were individually ear-tagged, using conventional livestock identification (ovina type; ALLFLEX Europe, Hawick, UK), and horns were color painted for easy individual recognition from a distance.

To ensure that females did not cycle during the experiment (and consequently modify their own behavior and that of other males and females), each female had a progesterone impregnated sponge inserted starting prior to the experiment (Chronogest $30 \mathrm{mg}$; Intervet, Milton Keynes, UK).

\section{Experimental arena}

We used an almost square 2.3-ha rye-grass sward flat field $(168 \times 156 \mathrm{~m})$ experimental arena. The average sward composition across the study was $84 \%$ Lolium perenne, 9.9\% Poa trivialis, Poa annua, Holcus lanatus, and Festuca rubra, 2.5\% Trifolium repens, 1.9\% Stellaria media, Rannunculus repens, Allopecurus pratensis, and Cerastium fontanum, and the remainder (1.7\%) unidentifiable dead material. To improve the spatial homogeneity of the sward $30 \mathrm{~kg} \mathrm{~N} /$ ha was applied by broadcast as $20: 10: 0$ (N:P:K) four weeks prior to the start of the experiment. The field was fenced and surrounded by similar fields. The arena offered the animals no shelter from the wind or rain. Four water points were distributed in the middle of each side of the field to minimize biased aggregations of the animals in one preferred side, although the use of the water points was negligible during the experiment. The arena was situated on a gentle slope $\left(9^{\circ}\right)$ at one side of a stream, and at the other side of the stream on the opposite slope an observation station was set up in a portable $1.45 \times 3 \mathrm{~m}$ plastic garden shed $100 \mathrm{~m}$ from the closest point of the experimental arena. To record the position of the animals in the arena we created a grid by inserting in the ground every $4 \mathrm{~m}$ a coded wooden peg, in total 1455 pegs, which could be identified with the aid of binoculars (magnification $10 \times 50$ ) from the observation station. We decided to start the experiment with a sward height of $\sim 10 \mathrm{~cm}$, which ensured enough forage to the animals and at the same time gave us a margin of sward growth that allowed us to visualize the code of the pegs during the whole experiment. To achieve $10-\mathrm{cm}$ sward height a flock of 150 Scottish Blackface sheep (Ovis aries) grazed the arena for three days before starting the experiment.

\section{Daily routine}

To enable the animals to became accustomed to the field, supplementation treatment and confinement pens they were put in the experimental arena one week before starting the observations and measurements. Every morning at 08:00 hours GMT the animals were gathered from the experimental arena with the assistance of a shepherd and dog and confined in a set of group pens at the top of the field. The group of animals that received the supplementation treatment were confined in individual pens and supplemented. After 20-30 minutes and after having checked that all of them had eaten the 
supplement, they were returned to the rest of the flock in the confinement group pens. All animals were dosed with n-alkanes pellets and fecal samples were collected when required and grazing activity logging devices were checked on each animal (see Intake and digestibility, below). All animals were released simultaneously into the experimental arena.

\section{Supplementation treatment}

We selected 10 males and 10 females, and each sex group was divided into two random groups of 5 animals. There were no significant differences in log-transformed body mass between groups within sex; males, supplemented $=32.7 \pm 1.46 \mathrm{~kg}[$ mean $\pm \mathrm{SD}]$, not supplemented $=34.2 \pm 1.85$; females, supplemented $=24.8 \pm 0.98$, not supplemented $=24.0 \pm 1.76$; ANOVA, males, $F_{1,8}=1.96$, $P=0.199$; females, $F_{1,8}=0.76, P=0.408$. Within sex, one group was supplemented and the other was the control group (not supplemented). For each animal in the treatment group we calculated the amount of feed (concentrate pellets) required to meet $30 \%$ of the daily energy requirements following MAFF (1975) and AFRC (1993) intake equations. Ruckstuhl and Neuhaus (2002) hypothesized that $20 \%$ is the minimum sexual dimorphisms in body size required to induce segregation in ungulates, and our $30 \%$ is well over this threshold. Every morning the animals were gathered and the supplemented group was fed concentrate pellets with the amounts calculated for each individual. The amount of concentrate pellets was calculated for each animal at the beginning and in the middle of the experiment to account for any variation in the body mass of the animals. The behavior of animals within each group (supplemented or control) should be more synchronized than the behavior between these groups, despite all of them being of the same body size. As a result, segregation between supplemented and control groups should emerge.

\section{Sward height and botanical collection}

Forage availability was estimated every five days during the experiment, starting on 16 May (six sampling days) by recording 40 measurements of the sward height from top to bottom of the field every $4 \mathrm{~m}$ using a sward stick (Barthram et al. 2000). Simultaneously, 40 samples of the sward were collected by hand plucking vegetation to a depth of $\sim 4 \mathrm{~cm}$, simulating grazing across the same transect and pooled within sampling day.

Vegetation samples of each of the six collection dates were separated into individual species components, freeze-dried, and weighed.

\section{Intake and digestibility}

Intake and digestibility were estimated using a nonintrusive method, the n-alkanes technique (Mayes et al. 1986, Dove and Mayes 1991). Long-chain n-alkanes are plant cuticular waxes that are absorbed to a very limited extent in ruminants, insectivores, other non-mammalian vertebrates and possibly invertebrate fauna (Bob Mayes, personal communication). Essentially the technique estimates the fecal output from concentrations of indigestible natural $n$-alkanes (odd number of $C$ chain) in feces and daily dose of artifitial n-alkanes administered (even number of $\mathrm{C}$ chain), where the recovery of the marker in feces is assumed to be between 0.86 and 0.98 for $\mathrm{C}_{36} \mathrm{n}$-alkanes (Mayes et al. 1986, Dove and Mayes 1991). Commencing on 16 May, each animal was dosed at 09:00 hours with a paper bung $(22 \times 16 \mathrm{~mm})$ carrying $90 \mathrm{mg}$ of $\mathrm{C}_{32} \mathrm{C}_{36}$ alkanes. This was administered orally (using a conventional balling gun) for a period of 10 days. On day 7, when the concentration of $n$-alkanes in the rumen would have reached a plateau (Bob Mayes, personal communication), daily fecal sampling commenced and continued until day 11 . The fecal samples were collected direct from the rectum and pooled within animal over the 5-day sampling period. Samples were then freeze-dried and milled prior to n-alkanes extraction and subsequent gas chromatography. Between the three sampling periods animals were given a 3-day rest period in feces collection and a 1-day rest from nalkanes dosing. It was considered that, following a 1-day break in dosing, a 3-day dosing period would reestablish the plateau of alkanes concentration in the rumen (Bob Mayes, personal communication).

\section{Cuticle microhistological analysis}

Cuticle microhistological analysis was used to estimate individual diet composition during three periods across the experiment. Cuticles in feces were prepared following Sparks and Malechek (1968) and Holechek et al. (1982) using subsamples from the daily collection of feces pooled within animal and period (same period as used in Intake and digestibility, above). The cuticle fragments in feces were compared against a reference collection of cuticles of the plant species present in the experimental arena and from the supplentation feed, aiming for $\sim 100$ identifiable plant fragments per sample (range $=82-410$ fragments, mean $=232$ fragments) .

\section{Recording behavior}

We used two exclusive categories of behavior: grazing and not grazing. Grazing was defined as the behavior in which the animal was engaged in grasping or severing the sward or when its head was down in an active position of searching for food between bites (Elaich et al. 1989, Wallis de Vries et al. 1998). Any other behavior was defined as not grazing, independently of whether the animal was standing or lying down.

Animal behavior was recorded 24 hours per day for five days each week across the experiment, except for $\sim 2$ hours per day (07:30-09:30 hours) to allow for gathering and handling the sheep and between Saturday morning and Monday morning. We adapted a TinytagPlus voltage-input data logger (part number TGPR-0704; Gemini Data Logger, Chichester, West Sussex, UK) using three internal tilt switches. This modified the current electrical input of the grazing logger when the angle of the 
longitudinal axis of the logger was greater than $14^{\circ}$ below the horizontal plane, which we defined as grazing position. Two switches overrode grazing positions when the transverse axis of the grazing logger was tilted more than $47^{\circ}$ under the horizontal plane in any direction. This happened when the animals were lying down with the cheek resting on the ground or with the head resting over their shoulder. The grazing loggers were fitted onto the neck of the animals using nylon webbing collars.

The accuracy of the loggers was evaluated with three nonexperimental Soay sheep for a period of two weeks, which resulted in a concurrence of $98 \%$ between the behavior recorded by the loggers and the real behavior of the animals as assessed by inspection of video tapes recorded with closed-circuit television equipment.

We set up the grazing loggers to simultaneously record the angle of the head of each animal every 30 seconds for five days using Tinytags Explorer datalogging software (supplied by Gemini). After that period the information of the loggers was uploaded into a portable computer, the loggers were reprogrammed using the same settings and redeployed. Collars were removed from the animals during the weekends. The activity files contained the date and time, within one second of accuracy, and voltage of each reading. The records of each file were thoroughly inspected to verify that no functioning errors were affecting the data set. The records that took place while the animals were gathered for daily handling plus 30 minutes after releasing them into the experimental arena were discarded. Voltage readings were transformed into behavioral binomial classes, grazing or not grazing, and from these records we calculated a synchronization index, as detailed in Assessing synchronization, below.

To help in the interpretation of possible differences in activity budgets between target groups that might be linked to differences in diet composition, digestibility or intake, we recorded bite rates (Hongo 1998, PérezBarbería and Gordon 1999), by counting the number of bites in 30 seconds when animals were grazing. Records in which grazing activity was interrupted by the animal lifting the head were eliminated and rerecorded.

\section{Recording spatial distribution}

Thirty minutes after daily release of the sheep into the experimental arena the spatial distribution of the animals (i.e., fixes) was recorded by direct observation using the scan technique (Altmann 1974). This was done between $\sim$ 09:30 hours and 15:30 hours GMT from Monday to Friday across the experiment, approximately every $15 \mathrm{~min}$, by two observers from the observation station, giving a total of 20 days of observations. The observers used the wooden-peg grid to fix the location of the animals, recording the identification code of the animal and the closest peg to the animal's head. To increase the precision of the location to within $2 \mathrm{~m}$ the observers divided, visually, the space between four pegs into four squares and assigned the position of the animal's head to one of these squares. These positions were finally transformed into Cartesian coordinates to be used in the analyses.

To minimize tiredness in the observers during the day, and the associated increase of human error, each observer recorded only the position of approximately half of the animals in the arena in any scan. The information was recorded on a lap-top computer by a third person. The 40 fixes of each scan were achieved in about four minutes. This lag caused an error in the relative position between animals when they were moving. To minimize this error, observations in which some of the animals were running or moving faster than grazing speed (in our case 10-15 steps/minute) were discarded in the field. To estimate the bias caused by these errors we visually divided the sheep into two groups, and each observer recorded the position of the sheep in only one of the groups, one observer starting at the right (or bottom) and the other at the left (or top) of the arena. Consequently, there were two fixes per sheep within a recording lag of $\sim 4$ minutes. This allowed us to estimate relative movement rates between sheep (position changes in four minutes) and test its effect in the aggregation patterns between groups.

\section{Statistical analysis}

Assessing errors in fixes.-To assess the error in fixes caused by the movement of the animals during the time taken to record the positions of the 40 animals, we used the double-fixes method described in Recording spatial distribution, above. As an estimation of error we calculated the distance between double fixes within individual animals and we also analyzed the frequency distribution of these distances to provide a description of the error of the spatial data set. The error was relatively small. The average distance that animals travelled during the average time that it took to record the position of the 40 animals was $3.5 \pm 6.61 \mathrm{~m}$ [mean \pm $\mathrm{SD}$ ], $n=478$ fixes) and the 0.95 quantile was $10 \mathrm{~m}$.

Assessing segregation.-Segregation between pair of groups $\mathrm{A}=\left\{a_{i}\right\}_{i=1}^{n}$ and $\mathrm{B}=\left\{b_{i}\right\}_{i=1}^{m}$, where $a_{i}$ and $b_{i}$ are the animals of groups $\mathrm{A}$ and $\mathrm{B}$, respectively (groups are levels within sex, size, and supplement treatments, e.g., group $\mathrm{A}=$ small males vs. group $\mathrm{B}=$ large males), and $n$ and $m$ are the number of animals in each group (in all cases $n=m$ ), was estimated by comparing the mean of the pairwise distances within groups against the mean of pairwise distances between animals of different groups. Formalizing the description, the mean distance between the animals within group A and within group B is

$$
\begin{aligned}
\bar{d}([\mathrm{AB}])= & {\left[\frac{2}{n(n-1)}+\frac{2}{m(m-1)}\right] } \\
& \times\left[\sum_{i<j \leq n} d\left(a_{i}, a_{j}\right)+\sum_{i<j \leq n} d\left(b_{i}, b_{j}\right)\right]
\end{aligned}
$$

where $d\left(a_{i}, a_{j}\right)$ and $d\left(b_{i}, b_{j}\right)$ are the distances between two animals of groups $\mathrm{A}$ and $\mathrm{B}$, respectively. 
The mean distance between groups is

$$
\bar{d}(\mathrm{~A}, \mathrm{~B})=\frac{\sum_{i=1}^{n} \sum_{j=1}^{m} d\left(a_{i}, b_{j}\right)}{n \cdot m} .
$$

The index of segregation used was calculated as $\mathrm{Seg}=$ $\bar{d}(\mathrm{~A}, \mathrm{~B})-\bar{d}([\mathrm{AB}])$. Positive values of the index indicate that both groups are relatively apart in comparison with the intra-group distances, which is also related to the clustering pattern of the animals of each group. Negative values are possible but unlikely, representing the trend of animals of different groups to form mixedgroup isolated pairs. The index was applied to specific pairwise groups defined in Table 1.

The null hypothesis was that the segregation index between the animals of two groups does not differ from the segregation index that would result if the identity of the animals was randomly permuted but preserving the fixes in each scan. The rationale behind this is that external events (e.g., disturbance, wind) affect the spatial distribution of all animals (i.e., all animals moving to one side of the field); but despite this, patterns of segregation are still possible in the new distribution caused by the disturbance.

Analytical assessment of the null hypothesis was performed using randomization tests, as the pairwise distances are not independent because the spatial position of animal $a_{i}$ is used $n-1$ times in the calculation of the $n(n-1) / 2$ pairwise distances within group, consequently overestimating the actual degrees of freedom of $n$ independent observations. One simulation is described by preserving the spatial distribution of scan $k$ and randomizing the identity of the animals of the two target groups. Then the index of segregation was calculated as described above and the value was stored in a vector. The process was repeated 1000 times for scan $k$ to create a distribution of the null hypothesis. Then, the 0.95 quantile of the distribution was calculated and the observed value of segregation obtained in scan $k$ was compared against the null distribution to assess for significant segregation. The process was repeated for the total number of scans.

The index of segregation calculated from the observed fixes for each scan was plotted across time using a lowpass filer (moving average) to show the evolution of the segregation during the experiment. In addition, we used finite fast Fourier transformation (FFT) to assess for possible cycles of the segregation index occurred during the experiment. The output of the FFT was plotted as a periodogram (period in hours against power, power being a measure of frequency); if the periodogram shows clear isolated peaks this reveals dominant cycles of segregation repeated every $n$ number of hours, as indicated by the period.

Assessing synchronization.-Behavioral synchronization was estimated within groups $\bar{s}([\mathrm{AB}])$ and between groups $\bar{s}(\mathrm{~A}, \mathrm{~B})$ (see Assessing segregation, above, for definitions of symbols) to be used as an index of synchronization, Sync $=\bar{s}([\mathrm{AB}])-\bar{s}(\mathrm{~A}, \mathrm{~B})$.

The synchronization index was calculated for each hour-period in the target groups (Table 1) across the experiment. Hour-periods with fewer than 60 records were removed from the analysis $(n=8)$, comprising a total of 436 hour-periods (average of records per hourperiod $=116.1 \pm 16.25[$ mean $\pm \mathrm{SD}]$.

Synchronization between animals of the same group $(\bar{s}([\mathrm{AB}]))$ was calculated as the summation of the number of records within hour-period for which the activity matched between two animals (i.e., activity matched if the activity of both animals of a pair was grazing or not grazing). This was calculated for all pairwise combinations between animals within groups, excluding those within the same animal (i.e., the same animal cannot be part of two different groups [thus, supplemented and not-supplemented groups are formed with different animals]). This was divided by all pairwise combinations within groups and the number of records per hourperiod. Analogously, we calculated synchronization between groups, but each pairwise combination only included animals of different groups.

Synchronization within group can be formulated as

$$
\begin{aligned}
\bar{s}([\mathrm{AB}])=1-\{ & {\left[\frac{2}{h n(n-1)}+\frac{2}{h m(m-1)}\right] } \\
& \times\left[\sum_{i=1}^{n} \sum_{j=1}^{m} \sum_{k=1}^{h}\left|\left\{a_{i}\right\}_{k}-\left\{a_{j}\right\}_{k}\right|\right] \\
& \left.\times\left[+\sum_{i=1}^{n} \sum_{j=1}^{m} \sum_{k=1}^{h}\left|\left\{b_{i}\right\}_{k}-\left\{b_{j}\right\}_{k}\right|\right]\right\}
\end{aligned}
$$

and synchronization between groups as

$$
\bar{s}(\mathrm{~A}, \mathrm{~B})=1-\frac{\sum_{i=1}^{n} \sum_{j=1}^{m} \sum_{k=1}^{h}\left\{a_{i}\right\}_{k}-\left\{b_{j}\right\}_{k}}{h n m}
$$

where $h$ is the number of activity records per particular hour-period and other symbols are as described in Assessing segregation, above. Positive values indicate that the synchronization between the animals within groups is higher that the synchronization of animals between groups. The null hypothesis was that the synchronization index between two groups does not differ from the synchronization index calculated if the identity of the animals was randomly assigned. The null hypothesis of no synchronization between groups A, B was tested using simulations. The allocation of the animals of the groups A and B was randomized 1000 times between groups A, B for each hour-period of activity records. The order in which the activity records within hour-period was recorded was preserved to maintain the activity pattern within animal. The rationale behind this is that we consider that the pattern of activity is mainly related to physiological processes or external events (e.g., night; a storm or any disturbance) 
and therefore it needs to be preserved since it characterizes specific activity patterns of each animal. The observed synchronization index for each hourperiod was compared against the corresponding quantile 0.95 of the distribution of the simulated synchronization to test the null hypothesis that synchronization within groups and between groups was the same.

We used FFT to reveal cycles of synchronization across the experiment. FFT was applied across the temporal series of hourly synchronization between the target groups of Table 1. The results of the FFT analysis were plotted in a periodogram, analogously as described above in Assessing segregation.

Correlation between synchronization and segregation.-Activity records were available every 30 seconds almost for the complete duration of the experiment $(n=$ 51686 records) as described above; however, the spatial distribution of the animals was recorded only every 15 minutes during daylight for a maximum of $6 \mathrm{~h} /$ day. To test whether segregation was the product of synchronization or vice-versa, we first calculated synchronization between target groups during the average time period (ATP) taken to record all the fixes of a scan, namely, synchronization at time zero $\left(t_{0}\right)$. It represents the synchronization index assigned to the moment when the spatial distribution of the animals was recorded. Then synchronization was calculated for ATP but varying the time where it was centered between $t_{[-15: 15]}$ minutes. Next, correlation coefficients between segregation at time $t_{0}$ and synchronization around $t_{[-15: 15]}$ were calculated. Significance of the correlation coefficients was calculated assuming normality and also corroborated using bootstrap resampling to ensure that the significance held without having to make any strong assumptions about the probability distribution of the correlation coefficients.

Synchronization and segregation calculations, hypotheses testing, and graphs were programmed using MATLAB (MathWorks 2006).

Behavioral activity.-To test for differences between target groups in time spent grazing and not grazing we used log-ratio analysis (Elston et al. 1996). Log-ratio analysis is well suited for compositional data sets, where, for example, the activity of an animal is expressed as $n$ nonindependent classes of different behaviors. To make the different $n$ behaviors independent of each other the compositional data are expressed as $n-1 \log$ ratios, where the denominator is one of the behavioral classes. The allocation of the behavioral class in the denominator can be selected for operational convenience due to the skew-symmetric property (Elston et al. 1996). We used, as the numerator, the daily time spent not grazing, and as denominator the daily time spent grazing, this was done for convenience to produce most of the $\log$ ratios positive. Log ratios were calculated for each animal/day across the experiment. Differences in behavior between target groups using the log ratios were assessed using linear mixed models applying the method of residual maximum-likelihood analysis (REML). A REML model was built using animals as a random source of variability and each pair of target groups as the fixed effect. REML uses the Wald-statistic test whose significance can be approximated by a chi-square distribution with the degrees of freedom of the fixed effect. The analysis was carried out using the GenStat 8 statistical package (VSN International 2005).

Diet composition, intake and digestibility.-Diet composition in feces estimated using cuticle analysis was pooled into the two major categories, grasses and dicotyledons, and the proportion of each was calculated discarding the minor categories, which represented only $<1.4 \%$. Log ratios for the proportion of grasses/proportion of dicotyledons were calculated and differences between pairs of target groups were assessed using a REML model in which each animal was fitted as a random effect and pairs of target groups as fixed effects. Analogously, differences in digestibility between target groups, using body mass and intake as covariates when pertinent, were also assessed using REML models.

\section{RESUlts}

\section{Segregation}

There was a strong sexual segregation across the experiment (male vs. female, Fig. 1a, b). The mean of the index of segregation was 15.88 (first-third quartiles = [7.85, 24.57], Fig. 3). The index of sexual segregation was significant in 237 scans $(96.7 \%)$ out of 245 scans (Fig. 1a). The periodogram did not reveal clear patterns of temporal segregation (Fig. 1c).

A similar pattern was found for the target groups small males vs. large females. Between these target groups the index of segregation across the experiment was well above zero $($ mean $=14.4$, first-third quartiles $=$ [3.88, 21.10], Figs. 2 and 3), with $59.6 \%$ of the scans showing significant segregation. The similar results found in male-female segregation and small males vs. large females are not surprising since these two pairs of groups are not mutually exclusive.

In the rest of the target groups designed to test the effects of body size and supplementation (Table 1) the amount of segregation across the experiment was negligible (Fig. 2). The percentage of scans in which significant segregation was observed varied between $3.7 \%$ and $6.9 \%$ (Fig. 2) and most values of segregation were tightly distributed around zero (males, small vs. large $=[-0.41,-1.90: 0.44]$; females, small vs. large $=$ $[-0.15,-1.20: 0.52]$; males, supplemented vs. not supplemented $=[-0.01,-1.19: 0.91]$; females, supplemented vs. not supplemented $=[0.01,-1.07: 0.57]$; mean, first and third quartiles, respectively, Fig. 3). Periodograms of segregation in all these target groups showed no evidence of cyclical patterns.

\section{Behavioral activity and synchronization}

The average proportion of daily time spent grazing by the animals across the experiment was $0.36 \pm 0.004$ 

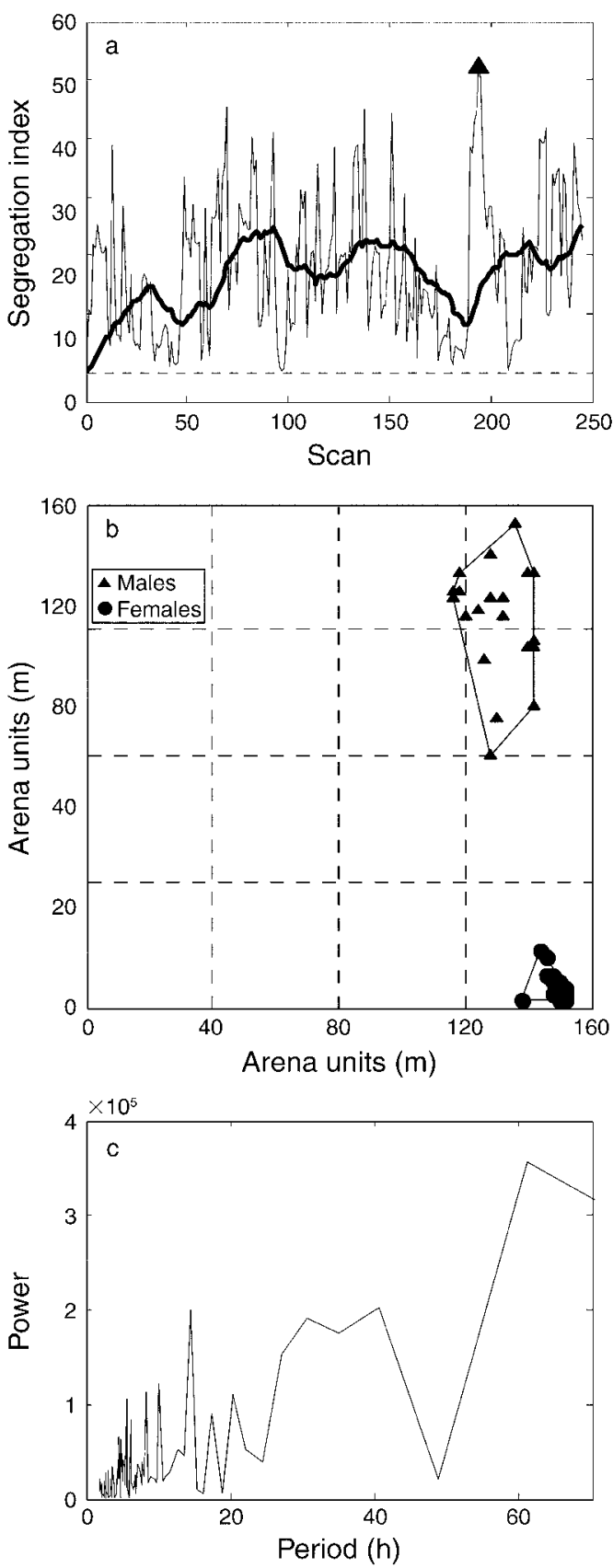

FIG. 1. (a) Sexual segregation index across the experiment (thin solid line). The line has been smoothed using a low-pass filter with a window size of 30 scans (thick line). Maximum value of segregation is marked with a triangle. (b) Minimumconvex-hull (the smallest convex set that contains the fixes) diagrams of the spatial distribution of the maximum segregation recorded, corresponding to the maximum value of (a). (c) Periodogram of the fast finite Fourier transformation (FFT) showing the cycles in the pattern of segregation of (a). Power is a measure of the strength for which a cycle in hours (Period) is repeated across the complete time series of the experiment. (mean $\pm \mathrm{SE}$ ), with little variation between target groups (range $=[0.32: 0.40]$, Fig. 4). The REML model on the $\log$ ratios of activity indicated that none of the target groups showed significant differences (Wald statistic $=$ 0.99 , $\mathrm{df}=1, P=0.32$, for the most conservative case of the four comparisons), however, females as a whole spent significantly more time grazing than males (Wald statistic $=4.16$, df $=1, P=0.041$, Fig. 4).

Overall the animals showed the characteristic pattern of summer daily foraging activity of ruminants in northern latitudes, with foraging bouts that ranged from minutes up to approximately one hour, irregularly distributed mainly during hours of daylight. Longer bouts of not-grazing took place during the night, mostly after midnight, interrupted by bouts of grazing activity that lasted only a few minutes (see Fig. 5a as an example
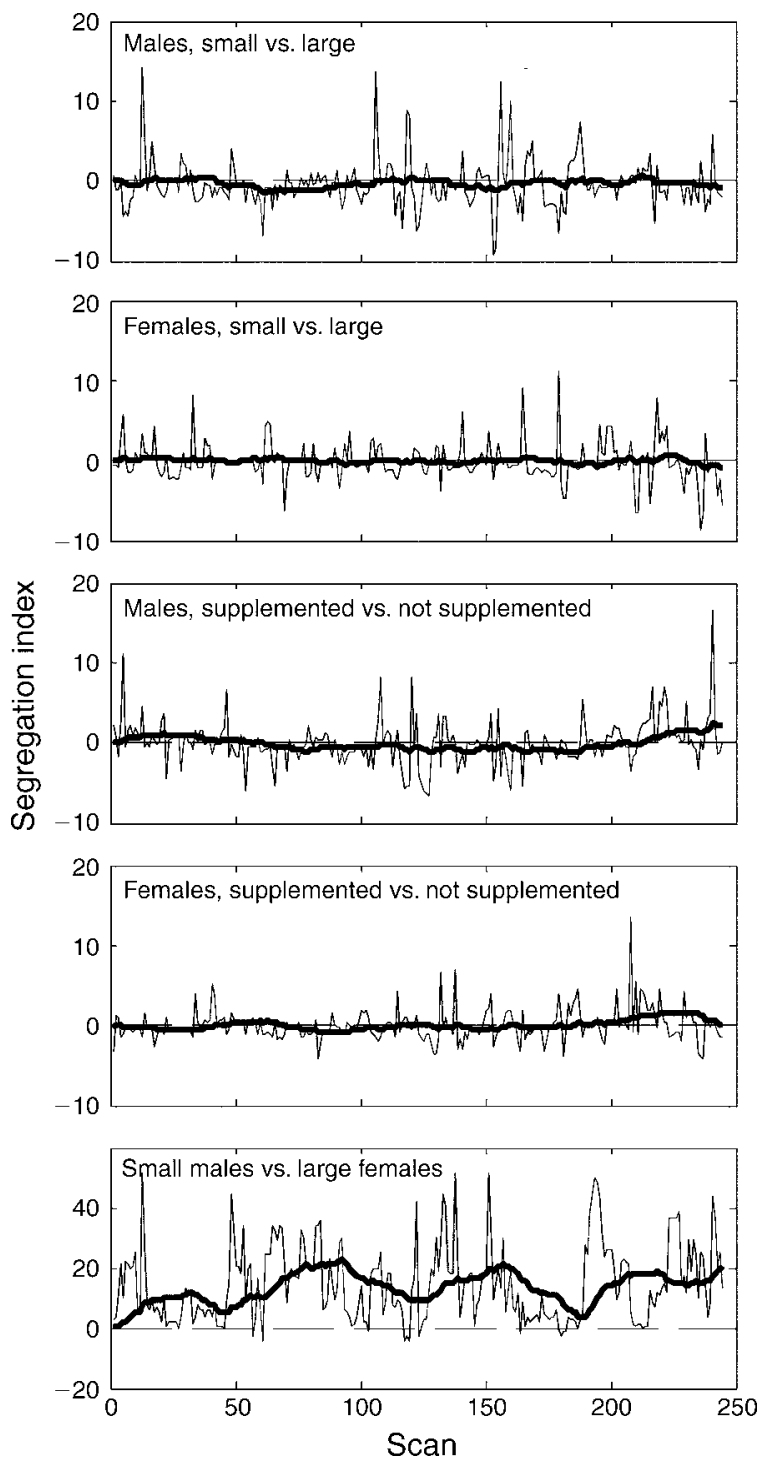

FIG. 2. Sexual segregation index of different target groups across the experiment. Details are as in Fig. 1a. 


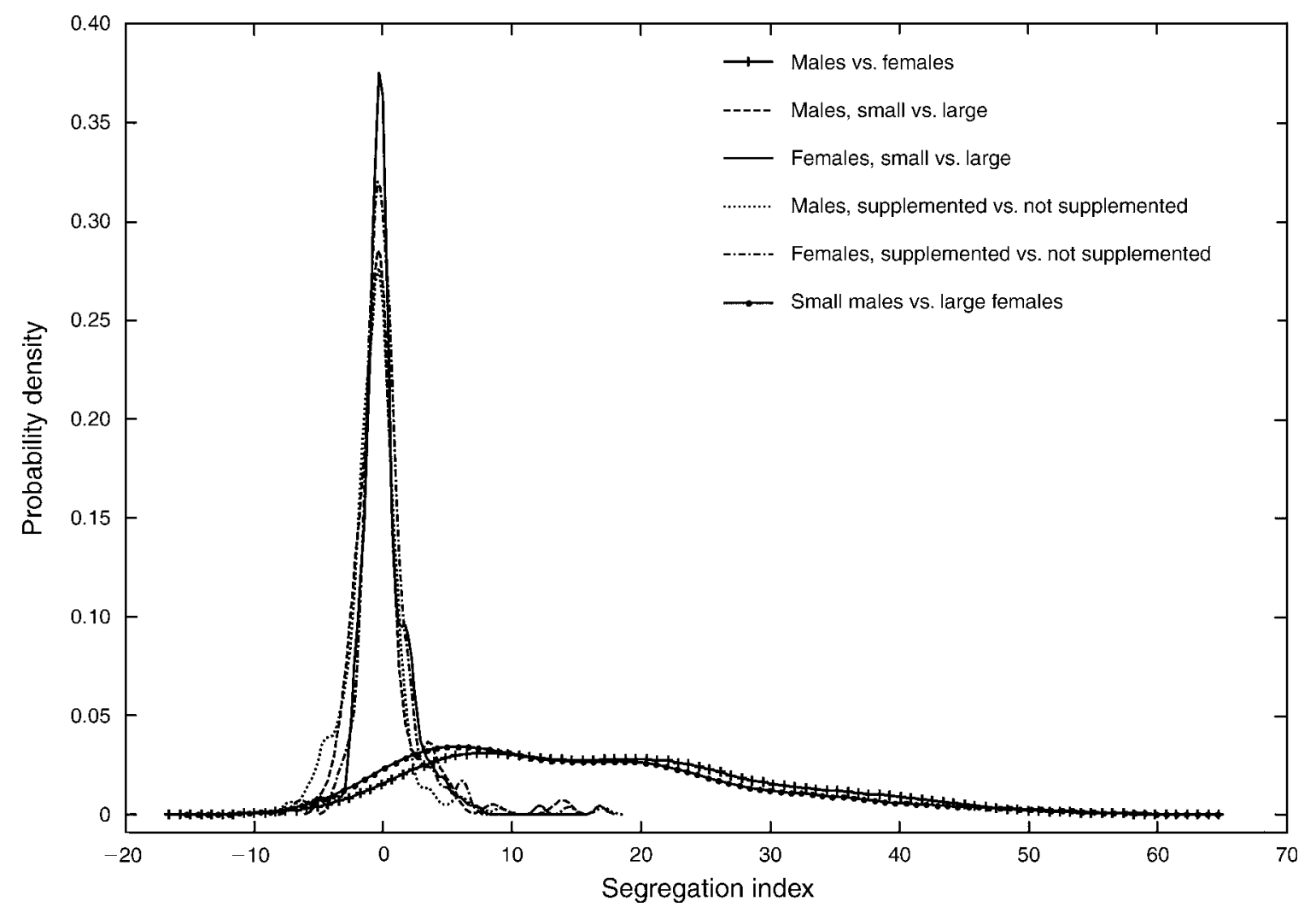

FIG. 3. Probability density of the distributions of the index of segregation between different target groups. Positive deviation from zero means that the average distance between animals of different groups is larger than the average distance between animals within a group (see Methods: Statistical analysis: Assessing segregation).

of the daily activity pattern of one random animal). The index of synchronization reflected this circadian activity pattern. Fig. 5b shows an example of the cycle of daily synchronization between sexes across the experiment.

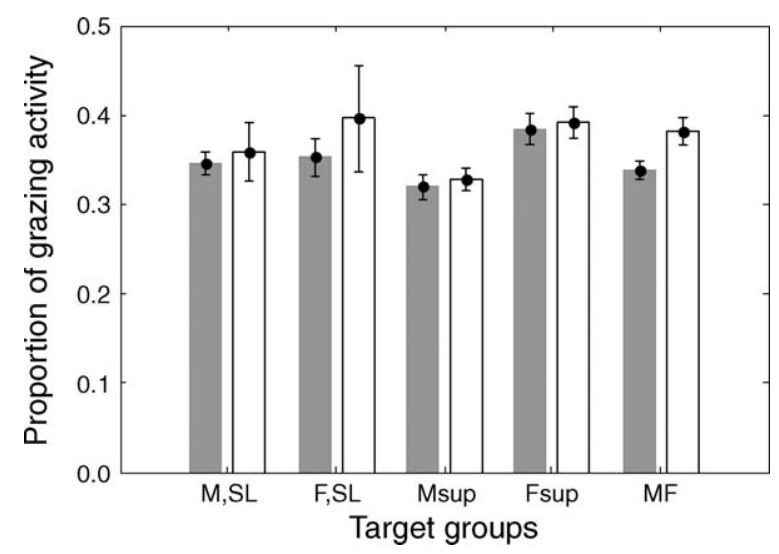

FIG. 4. Proportion of time (mean $\pm \mathrm{SE}$ ) spent grazing for different target groups across the experiment $(\mathrm{M}, \mathrm{SL}=$ males, small (solid bar) vs. large (open bar); F,SL = females, small (solid bar) vs. large (open bar); Msup = males, supplemented ( solid bar) vs. not supplemented (open bar); Fsup = females, supplemented (solid bar) vs. not supplemented (open bar); MF $=$ males (solid bar) vs. females (open bar).
Further evidence of a dominant circadian rhythm of activity is provided by the periodogram of the FFT. All target groups show a conspicuous peak in the periodogram at 22:00 hours, rather than the standard 24-h cycle due to the daily two hours missing because of animal handling (Fig. 5c-h).

Synchronization between groups was very high as indicated by the small values of the index (mean values ranged between -0.0350 and 0.255 ; first and third quartiles $=-0.0019: 0.0091$, Fig. 6). The probability density of the synchronization index of males vs. females and small males vs. large females was positively skewed, which indicated that synchronization within animals of the same sex was higher than synchronization between animals of different sex even after controlling for body mass. For example, within sex the animals were $75.5 \%$ of the time ( $n=437$ hour-blocks) more synchronized than between sex, and $68.9 \%$ of the time after controlling for body mass (small males vs. large females). Size had a much smaller effect on synchronization than sex; in males, animals of similar size were more synchronized than animals of different size only $29.3 \%$ of the time (males, small vs. large) and in females $29.8 \%$ of the time (females, small vs. large). The supplementation treatment had a bigger effect on synchronization than size but smaller than sex. Males that were supplemented 

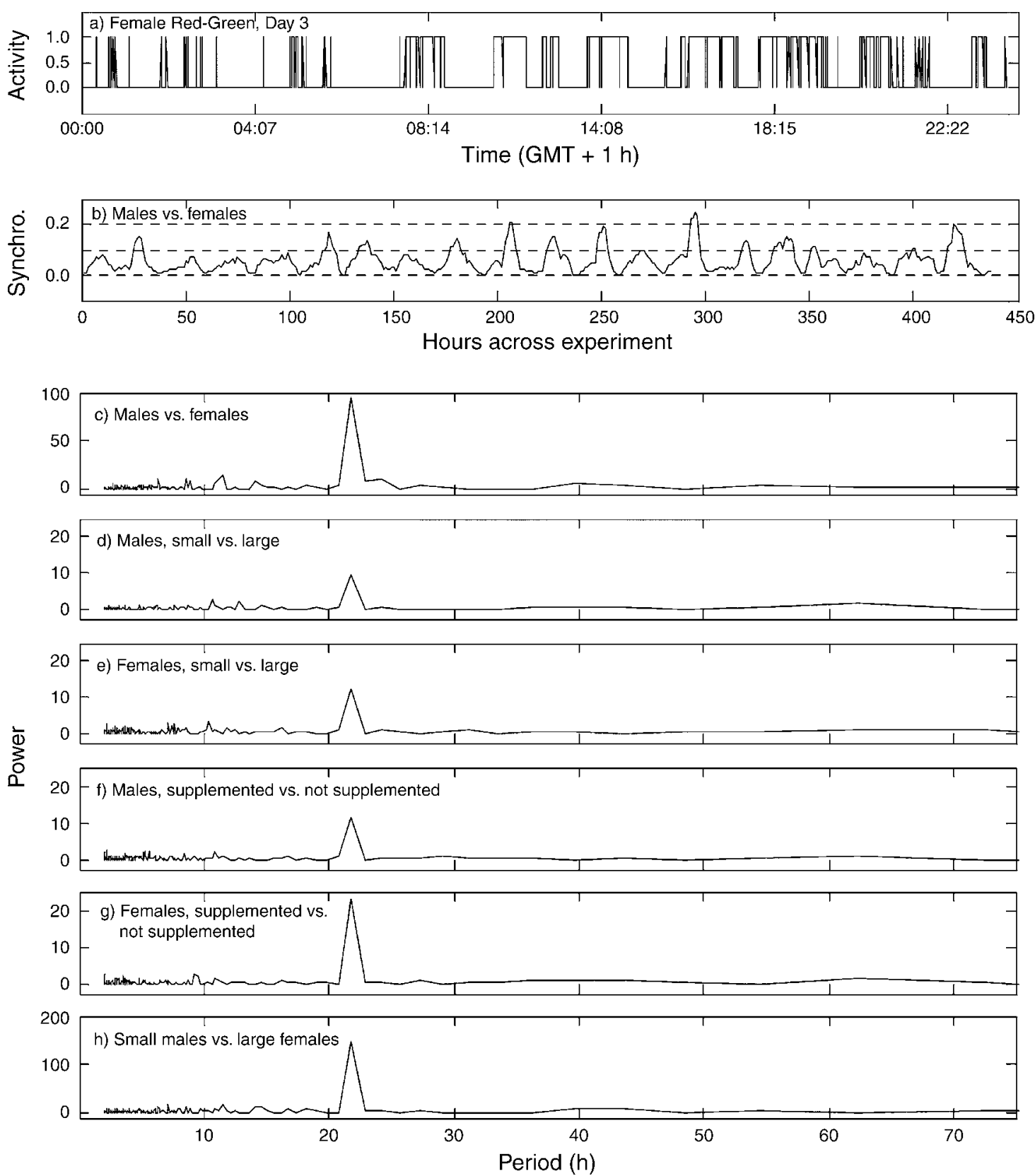

FIG. 5. (a) Example of binomial activity pattern (not-grazing $=0$ on $y$-axis; grazing $=1$ on $y$-axis) of animal Female Red-Green in day 3 of the experiment. In this example the activity was recorded by automatic grazing loggers every 30 seconds starting at 00:00 hours. Animals were handled in day 3 between 08:28 and 10:15 hours; therefore these records were excluded in the plot (see Methods: Study area and animals). (b) Example of synchronization between males and females across the whole experiment. Synchronization (Synchro.) was calculated as described in Methods: Statistical analysis: Assessing synchronization. The line has been smoothed for clarity using a low-pass filter with a window size of 5 hours. (c) Spectral representation of the fast finite Fourier transformation (FFT) of the data of (b). [Note: FFT was applied to the raw data set of (b), that is, without having been filtered.] Power is a measure of the strength for which a cycle in hours (Period) is repeated across the complete time series of the experiment. The $x$-axis has been constrained to the interval [1:70] since no major cycles were detected out of this range. A clear peak of power close to 100 indicates a dominant cycle in activity of approximately 22 hours. There are many shorter cycles but of much smaller power. (d-h) As described in (c) but representing the activity of different pairs of target groups. 


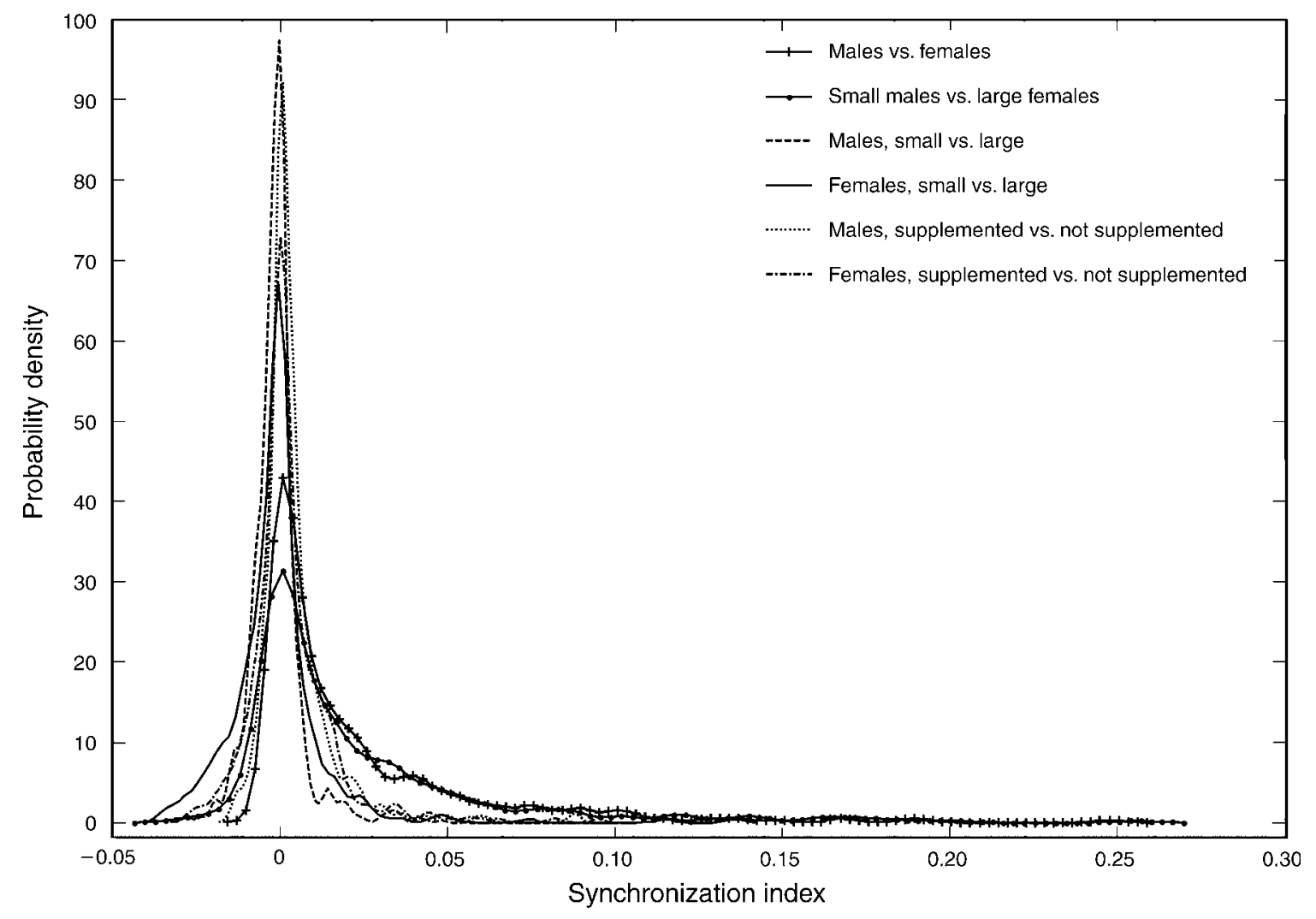

FIG. 6. Probability density of the distribution of the index of synchronization between different target groups. The pair groups males vs. females and small males vs. large females show the greater deviation from zero. A value of zero indicates maximum synchronization between groups. Positive deviation from zero means that the behavioral synchronization of animals within groups is greater than the synchronization of animals between groups (see Methods: Statistical analysis: Assessing synchronization).

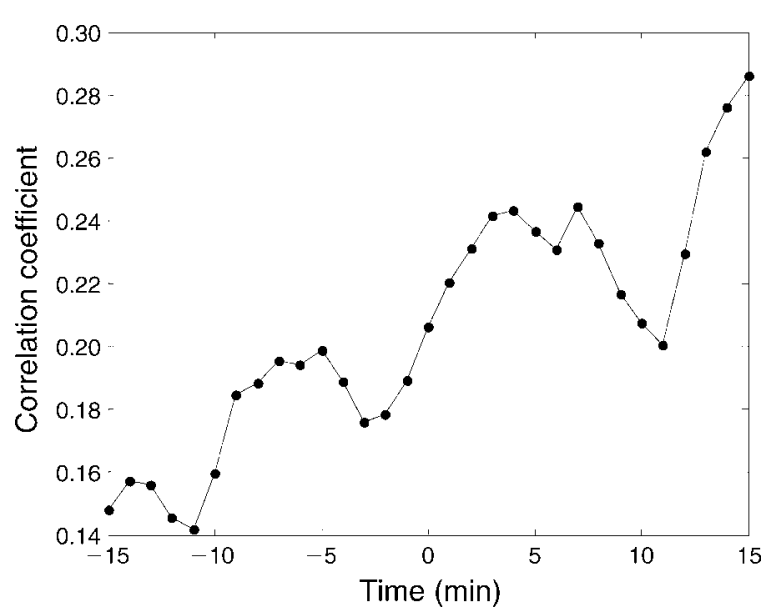

FIG. 7. Correlation coefficients between synchronization and segregation between males and females. The correlation is calculated within the average time interval taken to record the spatial distribution of the animals. This interval is centered at time $=0$ (time at which the scan was taken) and moves backward and forward up to 15 minutes, with correlation recalculated at each step (see Methods: Statistical analysis: Correlation between synchronization and segregation for details). All correlation coefficients are significant $(P<0.05)$. were $59.3 \%$ of the time more synchronized within than between males than received no supplementation, and a similar percentage $(48.7 \%)$ was found between supplemented and not-supplemented females.

\section{Synchronization and segregation: cause or effect?}

There was significant correlation between synchronization and segregation between males and females for any of the 31 time points of the interval $t_{[-15: 15]}$, with correlation coefficients between 0.142 and 0.286 (Fig. 7). For the male target groups small vs. large there were only nine out 31 significant values within the interval $t_{[-15: 15]}$. These nine values were scattered in the interval $t_{[-15: 0]}$. Small males vs. large females had also nine significant time points but these were scattered in the interval $t_{[0: 15]}$.

The correlation coefficients between synchronization and segregation between males and females presented a general ascending trend within the interval $t_{[-15: 15]}$ although with ups and downs across the trend (Fig. 7). In a closer interval around $t_{0}\left(t_{[-3: 3]}\right)$ there was a clear continuous ascending trend in the correlation coefficient. From three minutes before the spatial distribution of the animals was recorded $\left(t_{[-3: 0]}\right)$ the correlation increases from 0.176 to 0.206 , suggesting that segrega- 
TABLE 2. Residual maximum-likelihood (REML) model of differences in bite rates between target groups.

\begin{tabular}{|c|c|c|c|c|c|c|}
\hline \multirow[b]{2}{*}{ Group comparisons $\uparrow$} & \multicolumn{3}{|c|}{ Mean bite rate } & \multirow[b]{2}{*}{ Wald statistic } & \multirow[b]{2}{*}{ df } & \multirow[b]{2}{*}{$P$} \\
\hline & Group A & Group B & $\mathrm{SE}_{\mathrm{diff}}$ & & & \\
\hline Male vs. female & 0.006 & 0.019 & 0.0326 & 0.21 & 1 & 0.647 \\
\hline Male, small vs. large & -0.049 & 0.061 & 0.0890 & 1.51 & 1 & 0.219 \\
\hline Female, small vs. large & -0.026 & -0.031 & 0.0473 & 0.02 & 1 & 0.900 \\
\hline Small male vs. large female & -0.049 & -0.031 & 0.0519 & 0.07 & 1 & 0.787 \\
\hline Male, supplemented vs. not supplemented & 0.0195 & 0.045 & 0.0512 & 0.25 & 1 & 0.620 \\
\hline Female, supplemented vs. not supplemented & -0.006 & 0.086 & 0.0579 & 2.54 & 1 & 0.111 \\
\hline
\end{tabular}

\footnotetext{
$\dagger$ See Table 1 for description of groups.

$\$$ Means for the two respective groups being compared and standard errors of differences $\left(\mathrm{SE}_{\mathrm{diff}}\right)$ are log-transformed (original units: no. bites/s).
}

tion might be caused by increasing synchronization. The correlation coefficient continues its increase for the next three minutes $\left(t_{[0: 3]}\right)$ until reaching a value of 0.242 (Fig. 7), which suggests that the induced grouping might facilitate further synchronization.

\section{Sward composition}

The sward of the experimental arena was strongly dominated by Lolium perenne across the experiment, representing $84 \%$ of the dry matter among all species. The percentage of Lolium decreased across the experiment from $93 \%$ in the second week to $81 \%$ in the last week. There was a slight increase in the percentages of Poa trivialis and Festuca rubra throughout the study. Dicotyledon species represented a small percentage of the total dry matter $($ mean $=4 \%)$.

\section{Diet composition}

The only significant difference found in diet composition was between males and females. Males in comparison with females had a greater proportion of grass in their diets (log ratio grasses/dicotyledons: males $=1.05$, females $=0.92, \mathrm{SE}_{\mathrm{diff}}=0.0551 ;$ Wald statistic $=$ $5.9, \mathrm{df}=1, P=0.015$ ), which indicates that females were more selective than males since dicotyledon species in relation to grasses were in a proportion of 1:22.

When comparing males vs. females after having removed the effect of body mass (small males vs. large females) the results seems to be consistent, males ingest more grasses than females (log ratio for grasses/dicotyledons: males $=1.02$, females $=0.91)$, but this is not significant $(P=0.144)$.

The expected effect of body size on diet selection was not corroborated within sex, since neither small males $(P$ $=0.882)$ nor small females $(P=0.507)$ were more selective than large males or large females, respectively. Supplementation did not influence the diet composition achieved by grazing of males (log ratio grasses/dicotyledons: supplemented $=1.12$, not supplemented $=1.01, P$ $=0.254$ ) or females (supplemented $=0.85$, not supplemented $=0.93, P=0.407)$.

\section{Bite rates and digestibility}

There were no significant differences in bite rates between any of the target groups (Table 2). Across the study no general trend in bite rate was found between groups. In small vs. large males the bite rate was higher in the first week than in the last one (Wald statistic = 3.52 , $\mathrm{df}=3, P=0.014$ ) but in small vs. large females the bite rate was lower in the first week than in the last week (Wald statistic $=2.86, \mathrm{df}=3, P=0.036$ ).

The values of dry-matter digestibility were generally high (range $=0.76-0.87$ ) as was expected for highquality rye-grass sward in this season. Males achieved higher values of dry-matter digestibility than females even after having controlled for the effects of body mass and intake ( 0.84 vs. 0.82 , respectively, $P=0.015$, Table 3). Large males also had higher dry-matter digestibility than small males ( 0.83 vs. 0.85 , respectively, $P=0.031$, Table 3) after controlling for intake, but the same was not found between small and large females (Table 3). Supplementation reduced the digestibility for females after controlling for body mass and intake ( 0.81 vs. 0.83 , $P=0.013$, Table 3 ) but not in males.

\section{Changes in body mass}

Across the experiment males gained $13.5 \%$ mass in relation to their initial body mass while females only gained $3.8 \%$ (REML model on body mass, period $\times$ sex: Wald statistic $=16.2, \mathrm{df}=1, P<0.001)$. The supplementation treatment had no effect on the body mass of males or females across the experiment, as indicated by the nonsignificant interaction between $\operatorname{sex} x$ period $\times$ treatment $($ Wald statistic $=0.03, \mathrm{df}=1, P=$ $0.865)$.

\section{DisCUSSION}

The only significant segregation pattern found during the experiment was between sexes. However, the fact that a significant amount of segregation was also observed between animals of different sex but similar size (small males vs. large females) and that animals of the same sex did not segregate by body size is all evidence that does not support assumption $A_{1}$ and prediction $\mathrm{P}_{2}$ (Table 1). A striking result was that despite males and females having an average sexual dimorphism in body mass of $25 \%$ and differences in activity budgets (i.e., females spending longer time grazing than males), no differences in activity budgets were found between groups that show similar or even greater body-mass 
TABLE 3. Differences in digestibility (proportion of dry matter digested) after controlling for intake between target groups using REML analysis (animal as a random effect).

\begin{tabular}{|c|c|c|c|c|c|}
\hline Fixed term & Group A & Group B & Wald statistic & $\overline{\mathrm{df}}$ & $P$ \\
\hline Male vs. female $\dagger$ & 0.8448 & 0.8215 & 10.92 & 1 & $<0.001$ \\
\hline Male, small vs. large & 0.8317 & 0.8512 & 4.68 & 1 & 0.031 \\
\hline Female, small vs. large & 0.8242 & 0.8355 & 1.38 & 1 & 0.240 \\
\hline Small male vs. large female $\dagger$ & 0.8342 & 0.8378 & 0.12 & 1 & 0.725 \\
\hline Male, supplemented vs. not supplemented $\dagger$ & 0.8386 & 0.8464 & 1.27 & 1 & 0.260 \\
\hline Female, supplemented vs. not supplemented $\dagger$ & 0.8088 & 0.8253 & 6.23 & 1 & 0.013 \\
\hline
\end{tabular}

Notes: Group A and Group B are the predicted means by the model, in the respective order indicated in the Fixed-term column. Digestibility and intake were estimated using the n-alkanes technique. See Table 1 for a description of group comparisons.

$\dagger \log$ (body mass) was fitted as a covariant.

dimorphism (males, small vs. large $=26 \%$; females, small vs. large $=32 \%$ ). Consequently, the prediction that activity budgets are determined by differences in grazing-resting budgets induced by body-size differences seems to be inappropriate (against assumption $\mathrm{A}_{1}$ and prediction $\mathrm{P}_{1}$, Table 1$)$.

Assumption $\mathrm{A}_{1}$ (see Introduction) states that animals of small body size are less efficient at digesting fiber than larger ones, due to body-size digestive constraints (Demment 1982, Robbins 1993). The results on digestibility are not consistent with this expectation. We found sexual differences in digestibility, males digesting forage better than females, but these differences were independent of body size. Large males digested fiber significantly better than small males, according to what was expected, but the same was not corroborated between large and small females.

What could have been the cause of sexual differences in digestibility others than body size? As far as we know there is no evidence of sexual physiological differences in digestion efficiency once the effect of body size has been controlled (Robbins 1993, Pérez-Barbería et al. 2004). There are, however, behavioral differences that might help to explain the sex differences in digestibility found in our study. Our males spent less time foraging, and presumably more time ruminating than females, which might have helped them to achieve a better digestion of the forage via a better comminution of the ingesta (Gross et al. 1995, Pérez-Barbería and Gordon 1998). If this is what happened then a more efficient digestion was achieved by better comminution of food rather than by a longer retention of the ingesta in the digestive tract as the sexual dimorphism-body-size hypothesis and assumption $\mathrm{A}_{1}$ state.

It could be claimed that the sexual differences in digestibility were due to differences in diet composition. Although females included a larger proportion of dicotyledons in their diet in comparisons with males ( $11.91 \%$ vs. $9.61 \%$, respectively) the difference is not large enough to induce significant changes in digestibility and it can also be argued that the digestibility of our dicotyledon species is as high as the digestibility of the rye grass (MAFF 1975).
The supplementation treatment had a significant negative effect on the digestibility in females but not in males, although males showed the same trend. There are two plausible explanations. First, the combined digestibility provided by rye-grass grazing and the supplement could have been lower than the digestibility of rye grass only (MAFF 1975). Second, it is well documented that food supplements affect the microbial flora of ruminants by decreasing the ruminal $\mathrm{pH}$ (Ørskov 2002). This might have compromised the digestion of cellulose and subsequently the average digestibility, although the amount of supplement used was small and unlikely to have an adverse effect on digestion. These findings are consistent with the lack of effect that the supplement treatment had on the body mass of the animals, since by the end of the experiment the supplemented animals were not heavier than the control ones.

The supplement treatment did not have the predicted effect on time spent foraging or segregation (Assumption $\mathrm{A}_{2}$, Predictions $\mathrm{P}_{1}$ and $\mathrm{P}_{2}$, Table 1). Supplemented and control animals showed the same activity-budget pattern and spatial distribution irrespective of their sex. This means that supplemented animals, despite having met $30 \%$ of their daily energy requirements via morning supplementation, did not substantially modify their behavior in relation to the control group.

\section{How big is big enough?}

The rationale for the activity-budget hypothesis is based on the assumption that for a social group to become spatially coherent its members have to synchronize activities such as foraging and resting. For one member that is resting to become part of a foraging group, the animal has to interrupt its resting activity and join the moving group, although this change of behavior has an associated cost. The hypothesis assumes that the cost is high for animals of different size because the optimal allocation of time to different activities is likely to differ between size classes (Ruckstuhl 1999).

From the results of our present study there is no evidence that the claimed $20 \%$ difference in body mass can cause any significant segregation in our model species. Furthermore, differences in body mass of $26 \%$ between small and large males or even $32 \%$ between 
small and large females were insufficient to induce segregation due to body size. Consistently, the supplementation treatment that corresponded to $30 \%$ of the animals' daily energy requirements did not cause any significant segregation between treatments and control groups in either sex, because it did not have the expected reduction in foraging activity.

Ruckstuhl and Neuhaus (2005b) suggested that the loss of mass in African buffalo bulls that live in mixedsex groups in comparison with those that live in bachelor groups found by Prins and collaborators (Prins 1989, Prins and Iason 1989) could have been due to the associated costs of synchronization needed to live in mixed-sex groups. How costly would it have been for our animals to synchronize their behavior despite their big difference in body size?

Following this rationale we should expect that either the small or large body-mass groups (depending on which group is adapting its activity to the other group) would suffer mass loss across the experiment. Body mass increased across the experiment as would be expected at this time of the year (REML; Wald statistic $=294.67$, df $=1, P<0.001$ ), although males put on more mass than females (REML; Wald statistic $=47.31, \mathrm{df}=1, P<$ $0.001)$. However, the triple interaction sex $\times$ period $\times$ treatment was not significant (REML; Wald statistic $=$ $0.25, \mathrm{df}=1, P=0.620$ ) which indicates that the increase in body mass across the experiment was similar for treatment and control groups irrespective of sex. This might suggest that the costs involved in adapting the activity to other animals' activity are negligible under these experimental conditions.

These results of the analysis of body mass can be criticized because the costs that animals suffer in the wild are very different from the ones they may suffer in our experimental arena. For example, animals that rest while other animals forage are not at the risk of getting separated from the group because of the limited size of the arena.

There is a further problem when trying to measure the costs of activity synchronization between two groups. So far the implicit assumption is that group A suffers the costs of synchronizing its activity to that of group B. However, if both groups share the synchronization costs, then it will be more difficult to measure the effect since its magnitude would decrease.

It is likely that one of the main costs of behavioral synchronization between animals of different size is its negative effect on intake rate, which might affect body condition and reproductive performance (Veiberg et al. 2004). Reduction in foraging time as a consequence of the costs involved in synchronizing behavioral activity between animals of nonoptimal size could be compensated for by increasing intake rate, since in large herbivores daily intake is influenced by a combination of foraging time and intake rate (Shipley et al. 1994). There is experimental evidence that this is possible, at least in conditions of high food availability. Iason and collaborators (1999) found that sheep can compensate for the restriction of available daily grazing time (i.e., restricted overnight access to pasture) by increasing bite size. If bite size does not compromise food quality (i.e., less selective foraging strategy; Gordon and Illius 1988) then animals could counteract the time spent in other activities - for example, the costs involved in behavioral synchronization. This illustrates the case that animals can use some compensating strategies to minimize negative effects, and this seems possible, at least in the short term, since compensating strategies may be energy costly or might compromise other activities. However, in some cases costs may be so big that complete compensation is not possible.

The small spatial scale of the arena raises some issues, for example, is the size appropriate to test the predictions? The results suggest that the size of the arena in relation to the number of the animals and the accuracy of the fixes are adequate to allow us to detect the patterns of sexual segregation exhibited by the sheep. Consequently, segregation by size could also have been detected if the size or supplement sheep groups had shown a similar tendency of segregation to the one shown by the sex groups.

Due to the relatively small size of the arena our animals were able to be in virtually permanent visual contact and it is difficult to predict what would happen in a much larger arena. Perhaps the synchronization within groups would have been stronger had the sheep not been handled daily (which reset the study system once a day), and some segregation by size might have evolved. What emerges from our results is that the main segregation observed was by sex and not by size or supplement, which does not support the prediction.

Ruckstuhl and Kokko (2002) developed a model to demonstrate explicitly that sexual differences in activity budgets in sexually dimorphic species in body mass could, theoretically, produce sexual segregation. The model produced significant values of sexual segregation when sexual differences in activity budget increased. The sexual difference in activity budget was quantified by an activity ratio index, which estimated the feeding time necessary to meet maintenance requirements for the more active sex relative to the less active sex. Yearsley and Pérez-Barbería (2005) parameterized the model using real values of sexual dimorphism of extant ungulates to test whether the model could generate a significant amount of sexual segregation. Despite sexual dimorphism reaching $61 \%$ (male $>$ female), the maximum segregation produced for the model was not significant and about 10 times smaller than the maximum segregation presented by Ruckstuhl and Kokko (2002).

The question that remains unanswered is how big the differences in body size between animals have to be to create costs big enough to produce spatial segregation. Ruckstuhl and Neuhaus (2002) estimated that 20\% differences in body mass should suffice to produce 
segregation. Our study suggests that even differences of $32 \%$ do not suffice to produce any significant segregation. Would the activity-budget hypothesis be valid in cases of larger differences in body mass/size? If so, how general would this hypothesis be across extant ungulates species? From a total of 144 species of ungulates for which Yearsley and Pérez-Barbería (2005) presented information on sexual dimorphism in body mass, $48 \%$ had at least a sexual dimorphism of $20 \%$, but only $28 \%$ of the species had a sexual dimorphism $>32 \%$. This substantially reduces the number of potential species for which the activity-budget hypotheses may still apply; nonetheless, empirical support for the hypotheses is still needed.

\section{What is driving the segregation patterns of our groups?}

It has been questioned whether behavioral synchronization is the cause of segregation or rather its consequence (Barboza and Bowyer 2001, Bowyer 2004). The results of our present study are inconclusive since they suggest that increasing synchronization leads to segregation, but also that forming groups facilitates synchronization within animals of the same group, at least for a period of a few minutes around the time when segregation is measured. Consequently, it remains unclear whether synchronization is the cause or the effect of segregation, although it is not unreasonable to believe that there is feedback between both.

The segregation patterns observed in our experiment cannot be explained by the activity-budget hypothesis, nor by habitat segregation or the risk hypotheses since the experimental design removed any of the last two effects. In addition, Michelena et al. (2006) found that activity budgets and synchrony were insufficient to explain the social and sexual segregation observed in merino sheep (Ovis aries). This indicates that all attempts to test the activity-budget hypothesis using experimental designs, at least in ungulates, have failed.

One possible explanation of the results of our study could be the social affinity hypothesis (Bon et al. 2005, Conradt 2005, Michelena et al. 2005). But why should animals show affinity for animals of the same sex? F. J. Pérez-Barbería and J. M. Yearsley (unpublished manuscript) developed a model based on the social affinity hypothesis that claims to provide empirical evidence for the origins of sexual segregation. The rationale behind the model is that sexual segregation is an evolutionary behavior that acts as a facilitator for the development of competitive skills for mating success that will increase reproductive fitness, especially in males. The more challenging the contest between two opponents the greater the competitive skills they will develop in agonistic encounters. The model assumes that the most challenging contests take place when opponents are of similar size, and also that the success of parents in reproduction depends on their accumulated experience of challenging encounters. Within this evolutionary framework, social preferences evolve and as a conse- quence a significant amount of sexual segregation is produced. This could contribute to sexual segregation in polygynous species in any ecological scenario, but it remains a challenge to provide experimental evidence to support this model.

All in all the results of our study do not provide support for the assumptions and predictions of the activity-budget hypothesis. Our results mainly question the threshold of body-size dimorphism claimed to produce segregation between groups, which was insufficient to cause segregation under our experimental conditions. The significant differences found in digestibility associated with sex but not with size remain unexplained using the traditional argument that large body size facilitates fiber digestion.

We encourage researchers to carry out further experiments under controlled conditions to unravel the mechanisms involved in sexual segregation. One challenge is to provide experimental evidence of the socialaffinity hypothesis. This might be the evolutionary trigger of segregation at small spatial scale, although some other factors must also be operating to cause the large-scale segregation observed in some ungulate species in the wild.

\section{Acknowledgments}

Thanks to Cyril Charles, Carolina Marino, Pete Cram, Carol Kyle, and David Sim who assisted us during the experiment; Borja Álvarez, Bob Mayes, and Emily Green for their contribution with the alkanes analysis; the personnel of Glensaugh Research Station, David Hamilton, Donald Barrie, and David MacCartney; Craig MacEachern for looking after the Soay sheep flock through the year, despite his dislike for such a lively breed of sheep; Betty Duff and David Elston for their statistical advice; Luis Izquierdo, Dave Walker, Jack Lennon, and John Yearsley for their useful comments on programming; and Justin Irvine, Lorraine Robertson, and two anonymous referees for comments on the manuscript. R. Sorigner and F. J. Pérez-Barbería were granted travelling support by The Royal Society of Edinburgh. This research was funded by The Scottish Executive Environment and Rural Affairs Department and Plan Andaluz de Investigación Junta de Andalucía, Grupo RNM-118.

\section{Literature Cited}

AFRC [Agriculture and Food Research Council]. 1993. Energy and protein requirements of ruminants. $\mathrm{CAB}$ international, Wallingford, Oxon, UK.

Altmann, J. 1974. Observational study of behaviour: sampling methods. Behaviour 49:227-267.

Altringham, J. D., and P. Senior. 2005. Social systems and ecology of bats. Pages 280-302 in K. E. Ruckstuhl and P. Neuhaus, editors. Sexual segregation in vertebrates: ecology of the two sexes. Cambridge University Press, Cambridge, UK.

Barboza, P. S., and R. T. Bowyer. 2000. Sexual segregation in dimorphic deer: a new gastrocentric hypothesis. Journal of Mammalogy 81:473-487.

Barboza, P. S., and R. T. Bowyer. 2001. Seasonality of sexual segregation in dimorphic deer: extending the gastrocentric model. Alces 37:275-292.

Barthram, G. T., D. A. Elston, and G. R. Bolton. 2000. A comparison of three methods for measuring the vertical distribution of herbage mass in grassland. Grass and Forage Science 55:193-200. 
Bon, R., and R. Campan. 1996. Unexplained sexual segregation in polygamous ungulates - a defense of an ontogenic approach. Behavioural Processes 38:131-154.

Bon, R., J.-L. Deneubourg, J.-F. Gerard, and P. Michelena. 2005. Sexual segregation in ungulates: from individual mechanisms to collective patterns. Pages 200-217 in K. E. Ruckstuhl and P. Neuhaus, editors. Sexual segregation in vertebrates: ecology of the two sexes. Cambridge University Press, Cambridge, UK.

Bowyer, R. T. 2004. Sexual segregation in ruminants: definitions, hypotheses, and implications for conservation and management. Journal of Mammalogy 85:1039-1052.

Clutton-Brock, T. H., F. E. Guinness, and S. D. Albon. 1982. Red deer: behaviour and ecology of two sexes. University of Chicago Press, Chicago, Illinois, USA.

Clutton-Brock, T. H., and P. H. Harvey. 1983. The functional significance of variation in body size among mammals. Special Publications of the American Society of Mammalogists 7:633-663.

Conradt, L. 1998. Could asynchrony in activity between the sexes cause intersexual social segregation in ruminants? Proceedings of the Royal Society of London B 265:13591363.

Conradt, L. 2005. Definitions, hypotheses, models and measures in the study of animal segregation. Pages 11-32 in K. E. Ruckstuhl and P. Neuhaus, editors. Sexual segregation in vertebrates: ecology of the two sexes. Cambridge University Press, Cambridge, UK.

Conradt, L., and T. J. Roper. 2000. Activity synchrony and social cohesion: a fission-fusion model. Proceedings of the Royal Society of London B 267:2213-2218.

Conradt, L., and T. J. Roper. 2003. Group decision-making in animals. Nature 421:155-158.

Corti, P., and D. M. Shackleton. 2002. Relationship between predation-risk factors and sexual segregation in Dall's sheep (Ovis dalli dalli). Canadian Journal of Zoology-Revue Canadienne de Zoologie 80:2108-2117.

Croft, D. P., J. Krause, and R. James. 2005. Predation risk as a driving factor for size assortative shoaling and its implications for sexual segregation in fish. Pages 115-126 in K. E. Ruckstuhl and P. Neuhaus, editors. Sexual segregation in vertebrates: ecology of the two sexes. Cambridge University Press, Cambridge, UK.

Darwin, C. 1859. Origin of species by means of natural selection; or, the preservation of favoured races in the struggle for life. J. Murray, London, UK. 〈http://www. gutenberg.org/etext/1228>

Demment, M. W. 1982. The scaling of ruminoreticulum size with body-weight in East-African ungulates. African Journal of Ecology 20:43-47.

Demment, M. W., and W. H. Longhurst. 1987. Browsers and grazers: constraints on feeding ecology imposed by gut morphology and body size. Pages 989-1004 in O. P. Santana, A. G. da Silva, and W. C. Foote, editors. Proceedings of the IVth International Conference on Goats. Brazilia, Departamento de Difusao de Tecnologia. Empresa Brasileira de Pesquisa Agropecuária, Brasilia, DF, Brazil.

Dove, H., and R. W. Mayes. 1991. The use of plant wax alkanes as marker substances in studies of the nutrition of herbivores - a review. Australian Journal of Agricultural Research 42:913-952.

Elaich, A., A. Moukadem, and L. R. Rittenhouse. 1989. Feeding station behavior of free-grazing sheep. Applied Animal Behaviour Science 24:259-265.

Elston, D. A., A. W. Illius, and I. J. Gordon. 1996. Assessment of preference among a range of options using log ratio analysis. Ecology 77:2538-2548.

Gonzalez-Solis, J., and J. P. Croxall. 2005. Differences in foraging behaviour and feeding ecology in giant petrels. Pages 92-111 in K. E. Ruckstuhl and P. Neuhaus, editors.
Sexual segregation in vertebrates: ecology of the two sexes. Cambridge University Press, Cambridge, UK.

Gordon, I. J., and A. W. Illius. 1988. Incisor arcade structure and diet selection in ruminants. Functional Ecology 2:15-22.

Gross, J. E., M. W. Demment, P. U. Alkon, and M. Kotzman. 1995. Feeding and chewing behaviors of nubian ibexcompensation for sex-related differences in body-size. Functional Ecology 9:385-393.

Holechek, J. L., M. Vavra, and R. D. Pieper. 1982. Botanical composition determination of range herbivore diet: a review. Journal of Range Management 35:309-315.

Hongo, A. 1998. Selective grazing in pure leaf and leaf/culm mixtures of herbage grasses by sheep. Journal of Agricultural Science 131:353-359.

Iason, G. R., A. R. Mantecon, D. A. Sim, J. Gonzalez, E. Foreman, F. F. Bermudez, and D. A. Elston. 1999. Can grazing sheep compensate for a daily foraging time constraint? Journal of Animal Ecology 68:87-93.

Illius, A. W., and I. J. Gordon. 1987. The allometry of foodintake in grazing ruminants. Journal of Animal Ecology 56: 989-999.

Loe, L. E., R. J. Irvine, C. Bonenfant, A. Stien, R. Langvatn, S. D. Albon, A. Mysterud, and N. C. Stenseth. 2006. Testing five hypotheses of sexual segregation in an arctic ungulate. Journal of Animal Ecology 75:485-496.

MacFarlane, A. M., and G. Coulson. 2005. Sexual segregation in Australian marsupials. Pages 254-279 in K. E. Ruckstuhl and P. Neuhaus, editors. Sexual segregation in vertebrates: ecology of the two sexes. Cambridge University Press, Cambridge, UK.

MAFF [Ministry of Agriculture, Fisheries, and Food]. 1975. Energy allowances and feeding systems for ruminants. Her Majesty's Stationery Office, London, UK.

Main, M. B., and B. E. Coblentz. 1996. Sexual segregation in Rocky Mountain mule deer. Journal of Wildlife Management 60:497-507.

Main, M. B., F. W. Weckerly, and V. C. Bleich. 1996. Sexual segregation in ungulates - new directions for research. Journal of Mammalogy 77:449-461.

MathWorks. 2006. MATLAB. The MathWorks, Natick, Massachusetts, USA. 〈http://www.mathworks.com〉

Mayes, R. W., C. S. Lamb, and P. M. Colgrove. 1986. The use of dosed and herbage n-alkanes as markers for the determination of herbage intake. Journal of Agricultural Science 107:161-170.

Michaud, R. 2005. Sociality and ecology of the odontocetes. Pages 303-326 in K. E. Ruckstuhl and P. Neuhaus, editors. Sexual segregation in vertebrates: ecology of the two sexes. Cambridge University Press, Cambridge, UK.

Michelena, P., P. M. Bouquet, A. Dissac, V. Fourcassie, J. Lauga, J.-F. Gerard, and R. Bon. 2004. An experimental test of hypotheses explaining social segregation in dimorphic ungulates. Animal Behaviour 68:1371-1380.

Michelena, P., K. Henric, J. M. Angibault, J. Gautrais, P. Lapeyronie, R. H. Porter, J. L. Deneubourg, and R. Bon. 2005. An experimental study of social attraction and spacing between the sexes in sheep. Journal of Experimental Biology 208:4419-4426.

Michelena, P., S. Noel, J. Gautrais, J. F. Gerard, J. L. Deneubourg, and R. Bon. 2006. Sexual dimorphism, activity budget and synchrony in groups of sheep. Oecologia 148: $170-180$.

Mooring, M. S., T. A. Fitzpatrick, J. E. Benjamin, I. C. Fraser, T. T. Nishihira, D. D. Reisig, and E. M. Rominger. 2003. Sexual segregation in desert bighorn sheep (Ovis canadensis Mexicana). Behaviour 140:183-207.

Mooring, M. S., and E. M. Rominger. 2004. Is the activity budget hypothesis the holy grail of sexual segregation? Behaviour 141:521-530.

Neuhaus, P., and K. E. Ruckstuhl. 2002. The link between sexual dimorphism, activity budgets, and group cohesion: the 
case of the plains zebra (Equus burchelli). Canadian Journal of Zoology-Revue Canadienne de Zoologie 80:1437-1441.

Neuhaus, P., and K. E. Ruckstuhl. 2004a. Can the activity budget hypothesis explain sexual segregation in desert bighorn sheep? Behaviour 141:513-520.

Neuhaus, P., and K. E. Ruckstuhl. 2004b. Reply to Mooring and Rominger. Behaviour 141:531-532.

Ørskov, E. R. 2002. Trails and trials in livestock research. Andi Offset, Yogyakarta, Indonesia.

Pellegrini, A. D., J. D. Long, and E. A. Mizerek. 2005. Sexual segregation in humans. Pages 200-217 in K. E. Ruckstuhl and P. Neuhaus, editors. Sexual segregation in vertebrates: ecology of the two sexes. Cambridge University Press, Cambridge, UK.

Pérez-Barbería, F. J., D. A. Elston, I. J. Gordon, and A. W. Illius. 2004. The evolution of phylogenetic differences in the efficiency of digestion in ruminants. Proceedings of The Royal Society of London B 271:1081-1090.

Pérez-Barbería, F. J., and I. J. Gordon. 1998. Factors affecting food comminution during chewing in ruminants: a review. Biological Journal of the Linnean Society 63:233-256.

Pérez-Barbería, F. J., and I. J. Gordon. 1999. Body size dimorphism and sexual segregation in polygynous ungulates: an experimental test with Soay sheep. Oecologia 120:258267.

Pérez-Barbería, F. J., I. J. Gordon, and A. W. Illius. 2001. Phylogenetic analysis of stomach adaptation in digestive strategies in African ruminants. Oecologia 129:498-508.

Pérez-Barbería, F. J., E. Robertson, and I. J. Gordon. 2005. Are social factors sufficient to explain sexual segregation in ungulates? Animal Behaviour 69:827-834.

Prins, H. H. T. 1989. Condition changes and choice of socialenvironment in african buffalo bulls. Behaviour 108:297-324.

Prins, H. H. T., and G. R. Iason. 1989. Dangerous lions and nonchalant buffalo. Behaviour 108:262-296.

Robbins, C. T. 1993. Wildlife feeding and nutrition. Second edition. Academic Press, San Diego, California, USA.

Ruckstuhl, K. E. 1998. Foraging behaviour and sexual segregation in bighorn sheep. Animal Behaviour 56:99-106.

Ruckstuhl, K. E. 1999. To synchronise or not to synchronise: a dilemma for young bighorn males? Behaviour 136:805-818.

Ruckstuhl, K. E., and H. Kokko. 2002. Modelling sexual segregation in ungulates: effects of group size, activity budgets and synchrony. Animal Behaviour 64:909-914.

Ruckstuhl, K. E., and P. Neuhaus. 2000. Sexual segregation in ungulates: a new approach. Behaviour 137:361-377.
Ruckstuhl, K. E., and P. Neuhaus. 2001. Behavioral synchrony in ibex groups: effects of age, sex and habitat. Behaviour 138: 1033-1046.

Ruckstuhl, K. E., and P. Neuhaus. 2002. Sexual segregation in ungulates: a comparative test of three hypotheses. Biological Reviews 77:77-96.

Ruckstuhl, K. E., and P. Neuhaus. 2005a. Sexual segregation in vertebrates: ecology of the two sexes. Cambridge University Press, Cambridge, UK.

Ruckstuhl, K. E., and P. Neuhaus. 2005b. Activity asynchrony and social segregation. Pages 165-179 in K. E. Ruckstuhl and P. Neuhaus, editors. Sexual segregation in vertebrates: ecology of the two sexes. Cambridge University Press, Cambridge, UK.

Shine, R., and M. Wall. 2005. Ecological divergences between the sexes in reptiles. Pages 221-253 in K. E. Ruckstuhl and P. Neuhaus, editors. Sexual segregation in vertebrates: ecology of the two sexes. Cambridge University Press, Cambridge, UK.

Shipley, L. A., J. E. Gross, D. E. Spalinger, N. T. Hobbs, and B. A. Wunder. 1994. The scaling of intake rate in mammalian herbivores. American Naturalist 143:1055-1082.

Sparks, D. R., and J. C. Malechek. 1968. Estimating percentage dry weight in diets using a microscopic technique. Journal of Range Management 21:264-265.

Staniland, I. J. 2005. Sexual segregation in seals. Pages 53-73 in K. E. Ruckstuhl and P. Neuhaus, editors. Sexual segregation in vertebrates: ecology of the two sexes. Cambridge University Press, Cambridge, UK.

Veiberg, V., L. E. Loe, A. Mysterud, R. Langvatn, and N. C. Stenseth. 2004. Social rank, feeding and winter weight loss in red deer: any evidence of interference competition? Oecologia 138:135-142.

VSN International. 2005. GenStat, 8th edition. VSN International, Hemel Hempstead, UK.

Wallis de Vries, M. F., E. A. Laca, and M. W. Demment. 1998. From feeding station to patch: scaling up food intake measurements in grazing cattle. Applied Animal Behaviour Science 60:301-315.

Watts, D. P. 2005. Sexual segregation in non-human primates. Pages 327-347 in K. E. Ruckstuhl and P. Neuhaus, editors. Sexual segregation in vertebrates: ecology of the two sexes. Cambridge University Press, Cambridge, UK.

Yearsley, J. M., and F. J. Pérez-Barbería. 2005. Does the activity budget hypothesis explain sexual segregation in ungulates? Animal Behaviour 69:257-267. 